\title{
SEISMIC FRAGILITY ANALYSIS OF 3D VERTICAL IRREGULAR REINFORCED CONCRETE STRUCTURES
}

\author{
A. Ghanem ${ }^{(1)}$, D. Moon ${ }^{(2)}$, \\ (1) Ph.D. Student, University of Hawai 'i at Mānoa, aghanem@hawaii.edu \\ (2) Assistant Professor, University of Hawai 'i at Mānoa, dsmoon@hawaii.edu
}

\begin{abstract}
Because changes in the structure's occupancy significantly affect the mass distribution and the structure's behavior, changing mass distribution might make the building more irregular and vulnerable to the seismic ground motions. Many researchers tried to evaluate their seismic vulnerability. Most previous studies used simplified structural representations such as two-dimensional models that could not represent accurate seismic behavior from the coupling between lateral and torsional responses. For space structures with high irregularity, more realistic representations such as three-dimensional models are needed for the proper seismic assessment. To handle the computational challenge in deriving fragility curves, this research utilized a new structural reliability method that incorporates structural analysis and reliability analysis to efficiently and accurately calculate the failure probability with the first-order reliability method (FORM). This study investigates the seismic vulnerability of space reinforced concrete frame structures with varying vertical irregularity. More representative seismic fragility curves are derived with their three-dimensional analytical models. The significant effect of the structure's vertical irregularity on seismic vulnerability is highlighted.
\end{abstract}

Keywords: seismic vulnerability; Reinforced concrete; Vertical irregularity; Reliability Analysis; fragility curve. 


\section{Introduction}

Irregular buildings constitute a significant percentage of the modern urban infrastructure, leading to building structures with irregular distributions in their mass, stiffness, strength, and height. Any irregularity causes an abrupt change in the structure's strength or stiffness, which is not desirable in an earthquake-resistant system. After many deadly earthquake events, researchers find out that buildings with structural irregularity suffer the most from the earthquake. There are many instances of Irregularities, categorized into groups, including vertical structural irregularities and horizontal structural irregularities. Horizontal irregularities occur when the center of the mass is away from the center of rigidity. The seismic load acts at the center of the mass. Therefore, a torsional moment will be introduced, which caused the building to rotate about the center of rigidity. There are also vertical irregularities, such as various story height, building geometry setback, column offsets, and various mass on floors.

Since the earthquake usually carries out catastrophic damage, many efforts have been put into the seismic damage assessment, in which fragility curves are commonly used. Fragility curves are a valuable tool for seismic risk assessment and loss estimation of structural systems. Fragility curves describe the probability of failure of a building. They are lognormal functions that describe the probability of reaching or exceeding structural and nonstructural damage states. The curve shows the probability of failure versus peak ground acceleration and precisely estimates the inventory percentage that will suffer from the event.

In recent years, many researchers have conducted to assess the impact of vertical irregularities structures by generating fragility curves. Many vertical fragility curves were generated using Monte-Carlo simulation. However, structural failure is a low probability event. Sometimes, it requires thousands of trials to obtain one failure event, significantly increasing the computational time and cost. Researchers simplified the structural model with fewer structural nodes and idealized the 3D structure in a 2D frame. This method reduced the computation expense. However, the simplified 2D frame does not truly reflect the actual structural behavior under seismic load. 
Some researchers evaluate the probability of failure using analytical-based functions; this method does not require a massive structural analysis. However, since it is a pure analytical-based method. The complexity of the structure is also idealized, which reduces the accuracy of the failure probability. There is a similarity in all buildings that these researchers accessed. The structural irregularity was presented at the design stage of the structure. However, buildings were designed to last 50 to 100 years, sometimes even longer. In such a long span, there is a high chance that the building's occupancy would change, which might cause irregular mass distribution on the structure, and transform a regular building into a mass irregular building.

\section{Seismic Fragility Analysis Method}

Many research efforts have been devoted to measuring the seismic sensitivity of various structures and mitigating the predicted seismic risk since earthquakes cause catastrophic structural damages and economic losses. Earthquake fragility curves are commonly utilized for this, as they are critical in assessing seismic risk and estimating loss. Seismic fragility curves indicate the likelihood of a structure failing depending on predetermined damage conditions in the event of an earthquake. They plot the probability of failure vs a ground intensity variable such peak ground acceleration, as well as the inventory percentage that will be affected.

There are two main methods for creating seismic fragility curves. The first method is based on analytical functions of limit states, with failure probabilities computed as the likelihood of reaching a predetermined limit state condition in which structural capacity is less than seismic response or demand. The limit state function must be analytically represented using random variables in this manner. This method has a very limited use because obtaining the closed-form limit state function for comprehensive models and advanced structural analysis methods is almost impossible. As a result, the simulation-based strategy, which is the second approach, is more popular. The failure probability is calculated by dividing the number of failure cases by the total number of simulated cases in this approach. The failure is defined 
as the point at which the simulated structure response meets or exceeds the damage state criterion [4]. Any advanced structural analysis techniques (for example, inelastic pushover or dynamic response history analysis) can be applied to this method.

Many studies have used fragility curves to analyze the effect of vertical irregularity on the seismic performance of building structures. Hanan Al-Nimry used simple 3D analytical models to study building systems with vertical stiffness irregularities [5]. In the vulnerability study, the analytical function-based method was used. N. Achaean and colleagues investigated vertically uneven buildings with a soft story at various heights [6]. The fragility curves were obtained analytically from the limit state functions using $2 \mathrm{D}$ simplified models. Regular and irregular moment-resisting concrete and steel 2D frames with diverse irregularities [7] were compared by Nari et al. The failure probability was calculated using an analytical function-based method. Bhosale et al. looked at a number of different irregular building structures [8]. All of the structures were represented as 2D frames, and seismic fragility curves were calculated analytically. Mohammad et al. used 2D analytical models to assess the strength of irregular buildings [9]. The MCS was used to calculate the failure probabilities.

This study introduces and uses a state-of-the-art structural reliability analysis method to construct seismic fragility curves more inexpensively and precisely. This new method combines structural and reliability analysis methods to reduce computing costs and improve result accuracy [10]. The linking tool FERUM-ZEUS [11] was built in MATLAB and combines the structural analysis software ZEUS-NL and the reliability analysis tool FERUM (Finite Element Reliability Using MATLAB). The structural analysis is performed using ZEUS-NL, and the failure probability is calculated by FERUM using the first-order reliability technique (FORM). MATLAB is a platform that speeds up the computation process by using parallel computing techniques to run several analyses at the same time. Figure 1 depicts the overall fragility analysis method. 


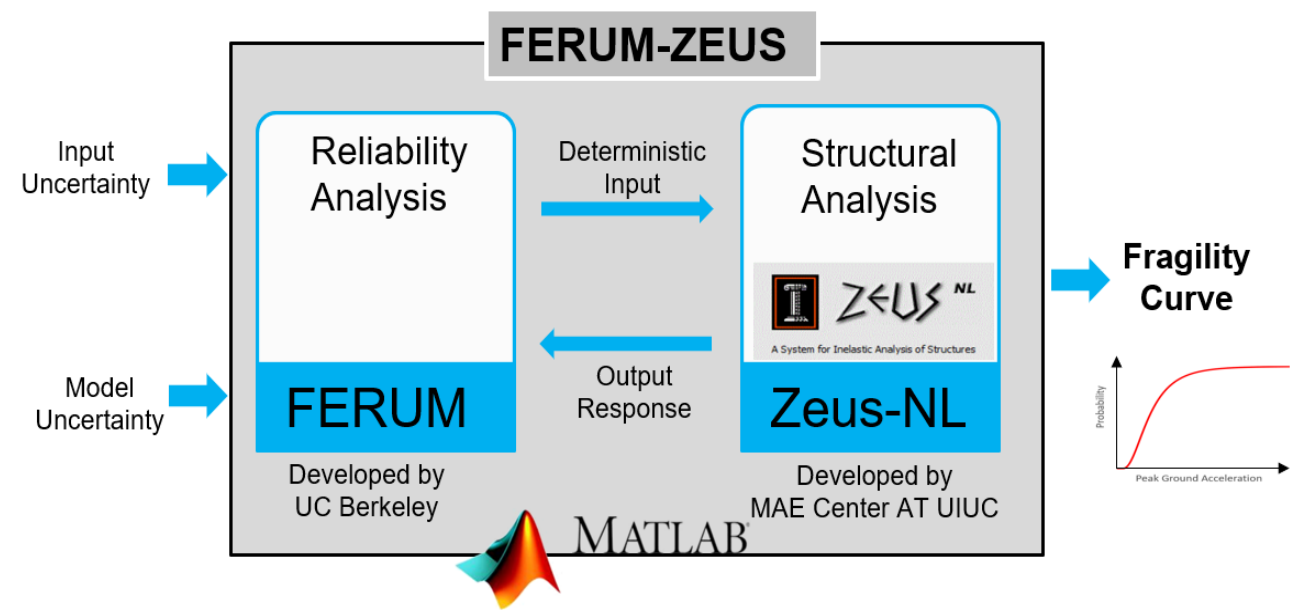

Fig. 1 - Integrated Fragility Analysis Framework

\section{Analytical Models and Input Earthquakes}

Three-story conventional reinforced concrete moment frames with three bays and three frames are the goal structures. The structures chosen are mostly intended for gravity loads and are not earthquakeprepared, but they represent a significant percentage of office buildings in the United States. In the ZEUSNL, 3D analytical models of the target structures are produced. The FEM model with all structural nodes is shown in Figure 2. There are 48 reinforced concrete columns, each with a 12-inch square cross-section. Beams are modeled using a reinforced concrete $\mathrm{T}$ section with an 18-inch depth and a 6-inch slab thickness.

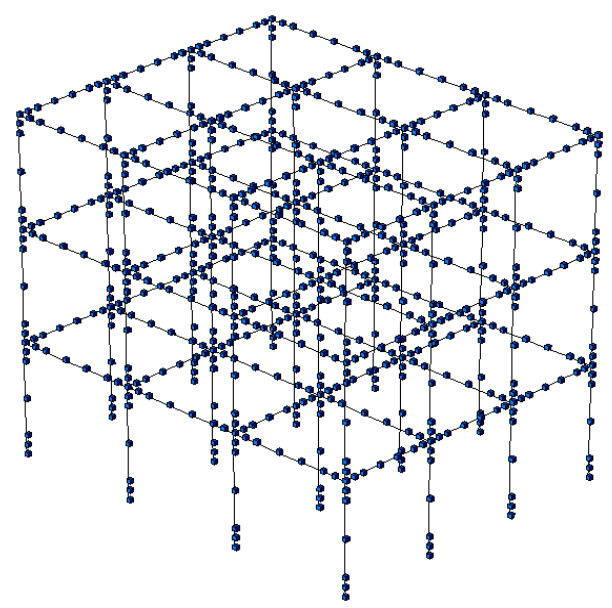

Fig. 2 - Structural Model in ZEUS-NL 
Actual material strengths are subject to significant uncertainty. The compressive strength of concrete can be affected by a variety of parameters, including temperature, curing technique, and vibration method. Steel and concrete strengths are thus represented as random variables in this study. The true compressive strength of concrete material can be considered to follow the log-normal distribution, according to Dr. Bartlett and Dr. MacGregor [12]. Steel reinforcement also follows the same pattern, according to another study [13]. Table 1 summarizes the log-normal distribution characteristics for the concrete and steel components utilized in the analysis.

Table 1 -Log-normal Distribution Parameters for Material Properties

\begin{tabular}{|c|c|c|}
\hline Material & Mean & Standard Deviation \\
\hline Concrete & $33.6 \mathrm{MPa}$ & 0.186 \\
\hline Steel & $336.5 \mathrm{MPa}$ & 0.107 \\
\hline
\end{tabular}

The total mass of the structure is assumed to remain constant, while the live load distribution can be altered. Because the structures under consideration are office buildings, the ASCE 7-16 design code [14] allows for a live load of 50 pounds per square foot (psf). The study considers fourteen alternative live load distribution situations, which are divided into three categories. The first group contains seven models (referred to as VIMEU) that are vertically irregular mass-eccentric models with uniformly distributed live loads on each floor plan. The second group contains seven types are classified as vertically irregular mass-eccentric models with concentrated living loads on half of each floor plan (referred as VIMEH). The remaining seven types are classified as vertically irregular mass-eccentric models with concentrated living loads on quarter of each floor plan (referred as VIMEQ). The vertical load distribution scenarios are similar to the first category, however the second and third groups include both in-plan and vertical irregularity. Figure 3 depicts the difference in the in-plan live load distribution (shown in yellow) and the associated in-plan eccentricities. Figure 4 depicts the seven vertical live load distribution scenarios. The two-way slab tributary approach is used to apply all loads as concentrated forces. 


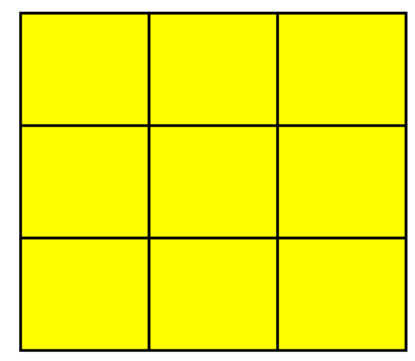

VIMEU

$e_{h}=0$

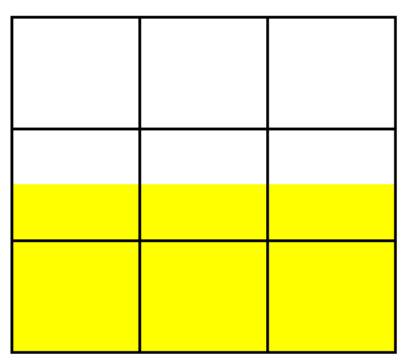

VIMEH

$e_{h}=17.2 \%$

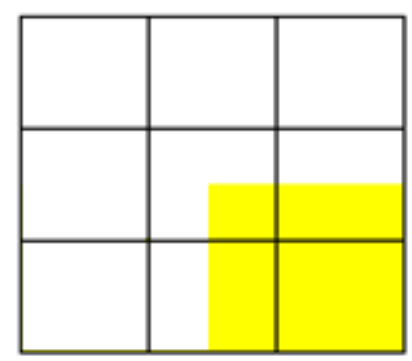

VIMEQ

$e_{h}=17.2 \%$

Fig. 3 - In-plan Live Load Distribution

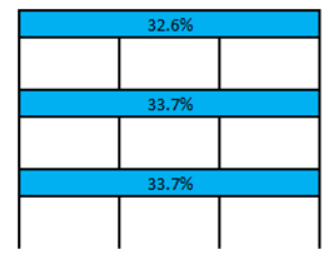

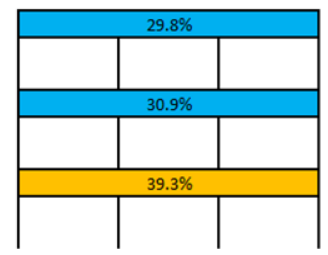

VIME01

$e_{v}=-4.19 \%$

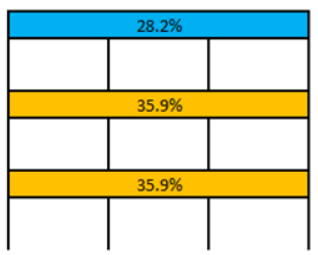

VIME12

$e_{v}=-3.35 \%$

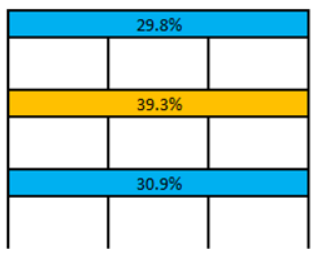

VIME02

$e_{v} \approx 0 \%$

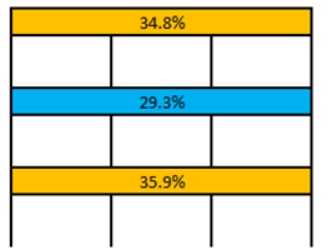

VIME13

$e_{v} \approx 0 \%$

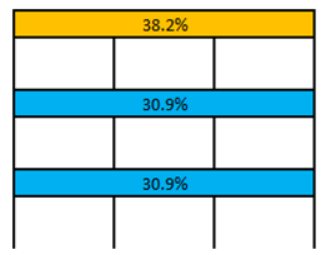

VIME03

$e_{v}=4.19 \%$

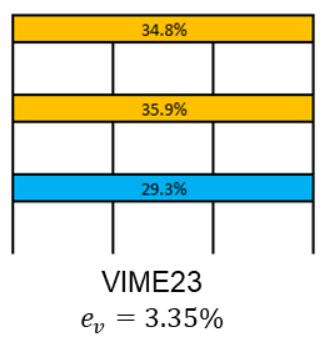

Fig. 4 - Vertical Live Load Distribution

The seismic analysis is based on ten earthquake records that can characterize various types of earthquakes. To model possible earthquake stresses acting on the structure, the ground motions are carefully determined based on the ratio of peak ground acceleration to peak ground velocity. Figure 5 shows the elastic response spectra and average response spectrum of the selected ground motion acceleration records, while Figure 6 shows the elastic response spectra and average response spectrum (shown in the thick red line). 


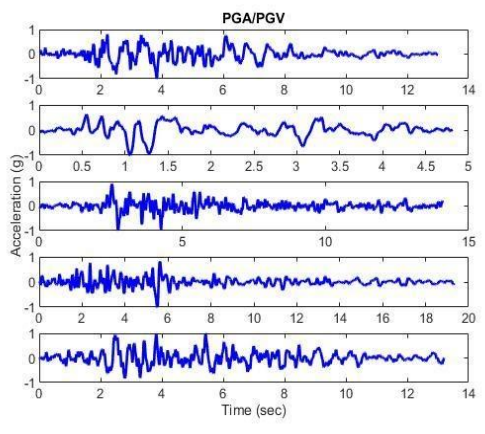

Fig. 5 - Earthquake Records

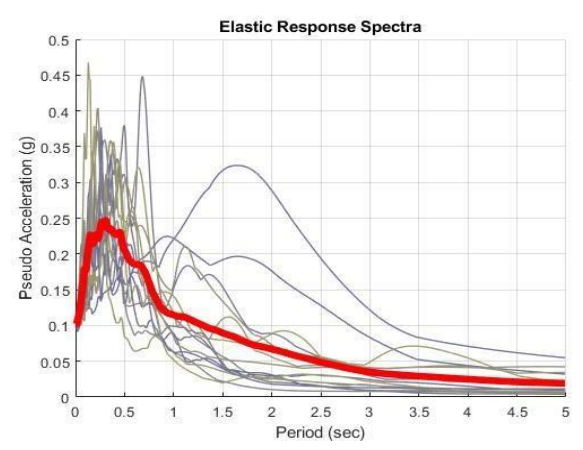

Fig. 6 - Elastic Response Spectra

\section{Seismic Fragility Analysis}

In the proposed fragility analysis, a dynamic response history analysis is conducted in ZEUS-NL, and the structural analysis results are sent to FERUM for the reliability analysis. In order to determine whether the structure fails according to the predefined damage condition, the limit state criteria that quantify the seismic capacity are typically obtained from the pushover analysis. Instead, this study adopts eight limit states based on the maximum allowable drift ratio values, which are $0.25 \%, 0.50 \%, 0.75 \%$. $1.00 \%, 1.25 \%, 1.50 \%, 1.75 \%$ and $2.00 \%$. The fragility curves at eight limit states are combined to draw the fragility surface. The use of eight limit states rather than typically employed three or four limit states is practically possible as the proposed method is highly computationally efficient.

In this study, fourteen prototype 3D frame models are analyzed with ten earthquake records and eight limit state definitions. This sums up to a total of 2730 cases. To decrease computation time, a modification is made so that parallel computing can be incorporated into the analysis. The total computation time is reduced to two weeks to derive all fragility curves with two ordinary personal computers with six Intel i7 CPU cores. The fragility analysis does not generate the fragility curve automatically; it provides a series of data points following a specific trend. A regression analysis is followed to determine analytical fragility curve functions assuming the log-normal cumulative distribution. 


\subsection{Fundamental Periods}

The eigenvalue analysis is performed for all studied models, and Figure 7 compares their first natural periods. The result shows that the models of VIME03 and VIME23 have longer periods than the other models, which coincides with the expectation that more loads on higher floors result in a more flexible system. Also, it is expected that those models would suffer more from the increasing overturning moment.

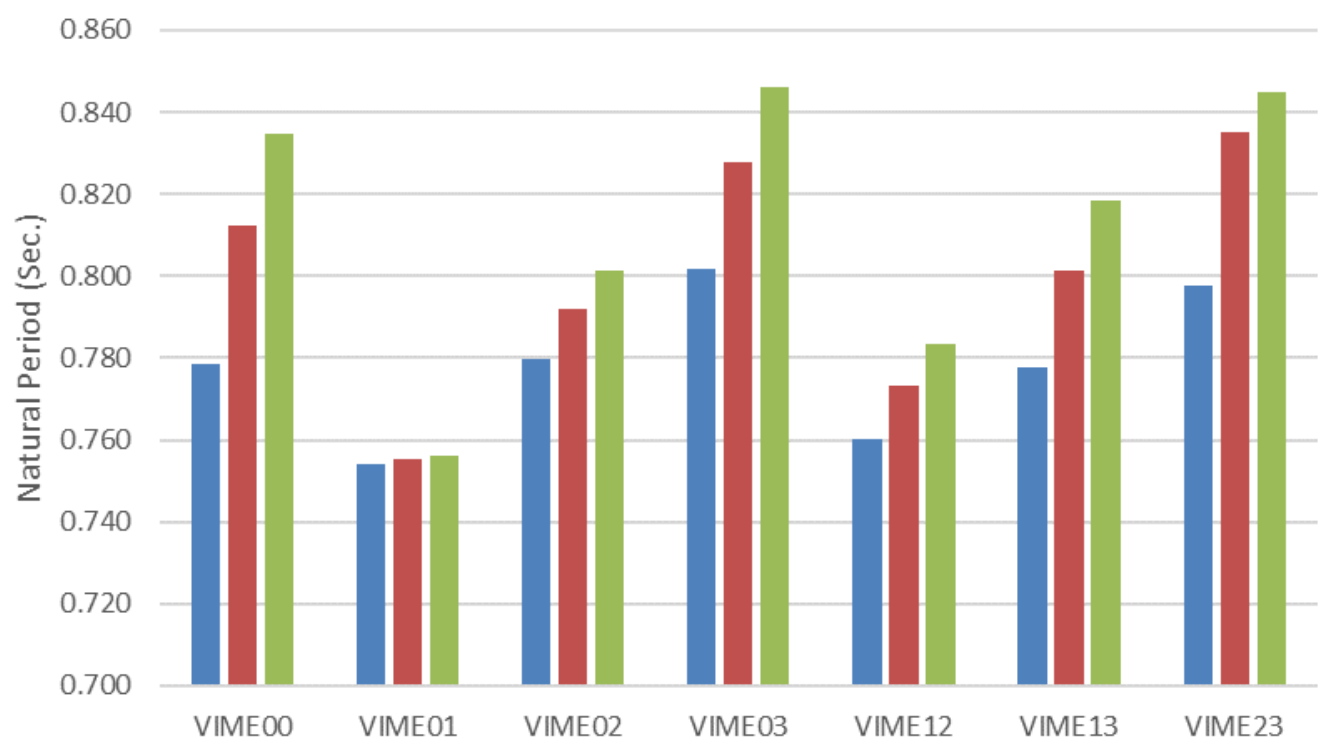

Fig. 7 - Fundamental Periods of Studied Models

\subsection{Fragility Curves}

Under the proposed framework, seismic fragility curves for studied reinforced concrete frame structures with vertical and in-plan irregularities are successfully derived. Fragility curves are assumed to be cumulative log-normal distribution functions, and they are obtained from the least square curve fitting. Selected fragility curves are shown in Figure 8, and each plot has smoothed fragility curves for eight limit states. The figure legend is based on the model reference name and the allowable drift ratio of the limit state. The fragility curve of the $0.25 \%$ limit-state is moved to the left of one of the $2.00 \%$ limit-state. It is 
noteworthy that seismic fragility curves are greatly affected by the structural irregularity in elevation as well as in plan.
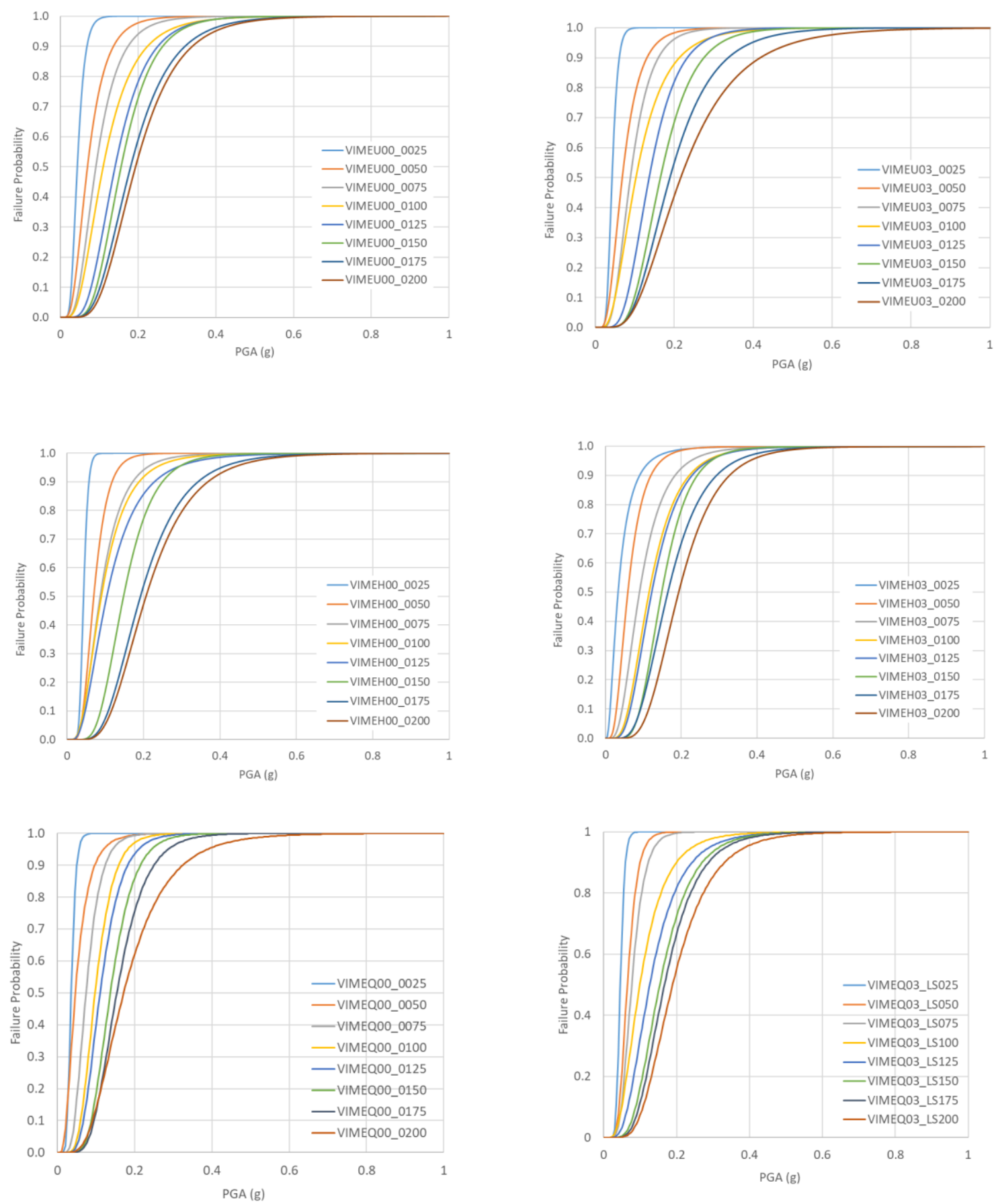

Fig. 8 - Selected Fragility Curves 
The limit state function is defined as the structural supply (or capacity) minus seismic demand (or response). When the limit state function is much larger than zero, the structure would not fail as there is enough seismic capacity for the expected seismic demand (i.e., the supply is much larger than the demand). In fact, the limit state function value is closely related to the failure probability. Figure 9 plots the failure likelihood versus the initial limit state function for the selected model. As expected, the failure probability increases with the decrease of the limit state function, and this shows the relation between differences in seismic supply and demand and failure probabilities. Note that the computational cost can be saved considerably by limiting the fragility analysis within the range of the trend line and by assuming the failure probability outside this range as either 0 or 1 .

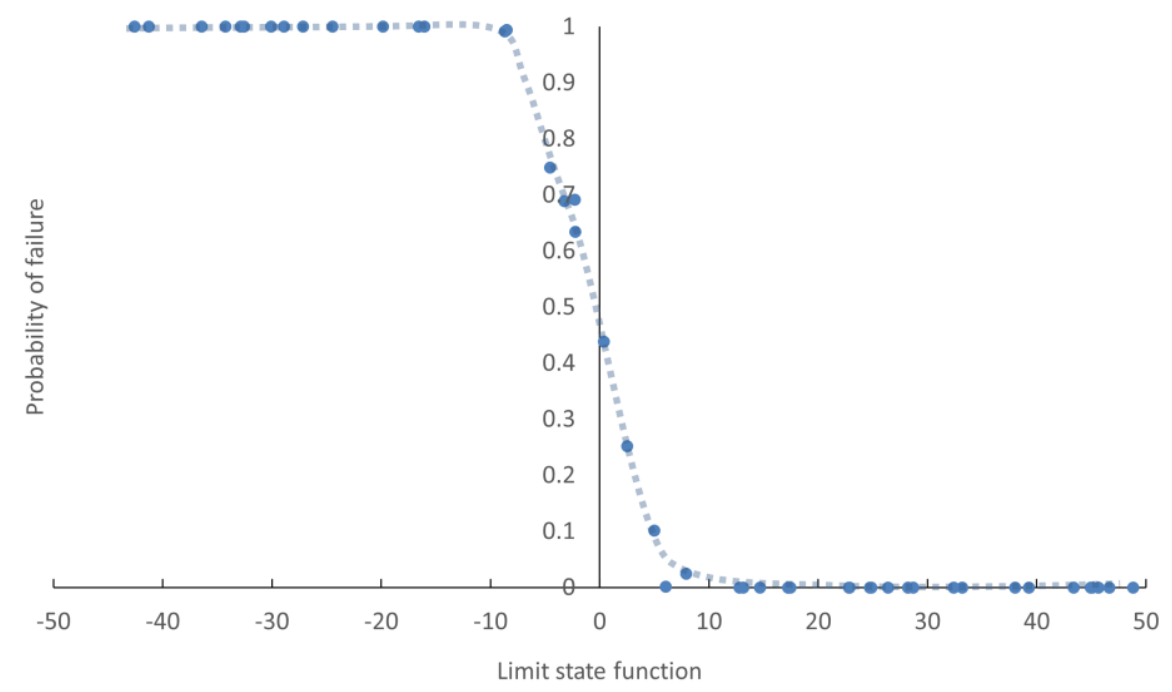

Fig. 9 - Failure Probability vs. Limit State function (VIMEU03 Model with 1.75\% Limit State)

To assess the impact of mass irregularity on seismic performance, a VIMEH model having high vertical irregularity is compared to the VIMEH model that does not have any vertical irregularity. Figure 10 shows fragility curves for VIMEH00 and VIMEH03 models at the limit state of the $1.00 \%$ allowable drift ratio. The VIMEH03 model has much higher failure probabilities when compared with the VIMEH00 model. It appears that at the peak ground acceleration of $0.16 \mathrm{~g}$, the probability of failure of VIMEH03 is $10 \%$ higher than that of VIMEH00. 


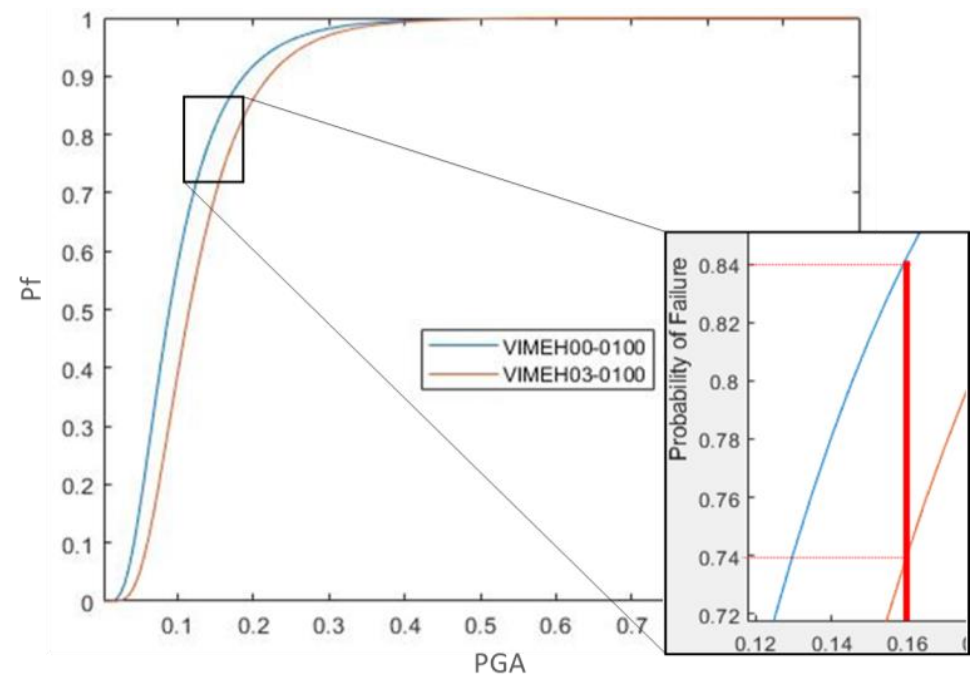

Fig. 10 - Effect of Vertical Irregularity on Fragility Curves

Fig. 11 compares fragility curves of VIMEU13 and VIMEH13 models with eight different limit states. This clearly shows that the in-plan irregularity makes the reinforced concrete frame structures more susceptible to earthquake loading, as repeatedly found in the previous studies.

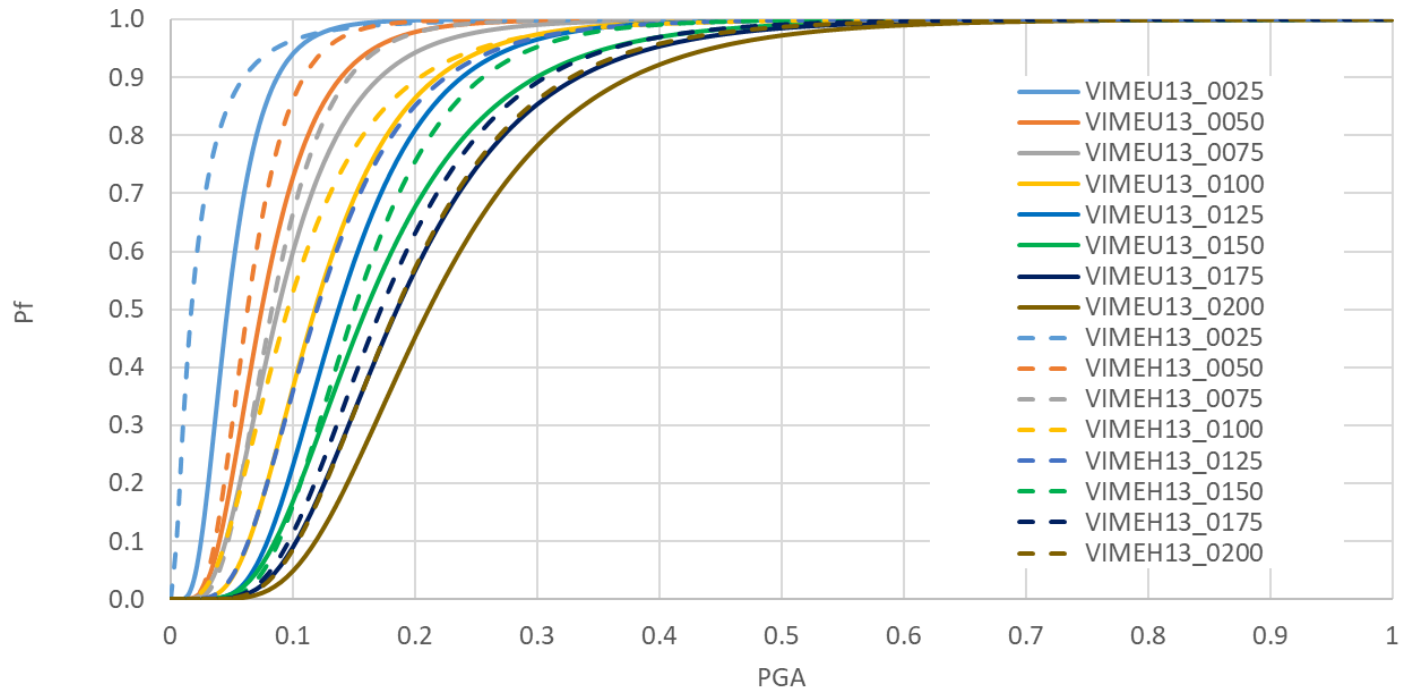

Fig. 11 - Effect of In-plan Irregularity on Fragility Curves 


\subsection{Fragility Surfaces}

Fig. 12 plots the seismic fragility surfaces of selected reinforced concrete frame structures with vertical and in-plane irregularities. The fragility surface is constructed from the derived fragility curves for all eight limit states. As visibly shown, the different levels of in-plan and vertical irregularities produce meaningly different seismic fragility surfaces. The failure probability increases with the stricter damage state definition. If any simulation-based method such as MCS is applied to the same vulnerability analysis, it would be practically impossible to derive the facility surface owing to the extremely expensive computational cost.

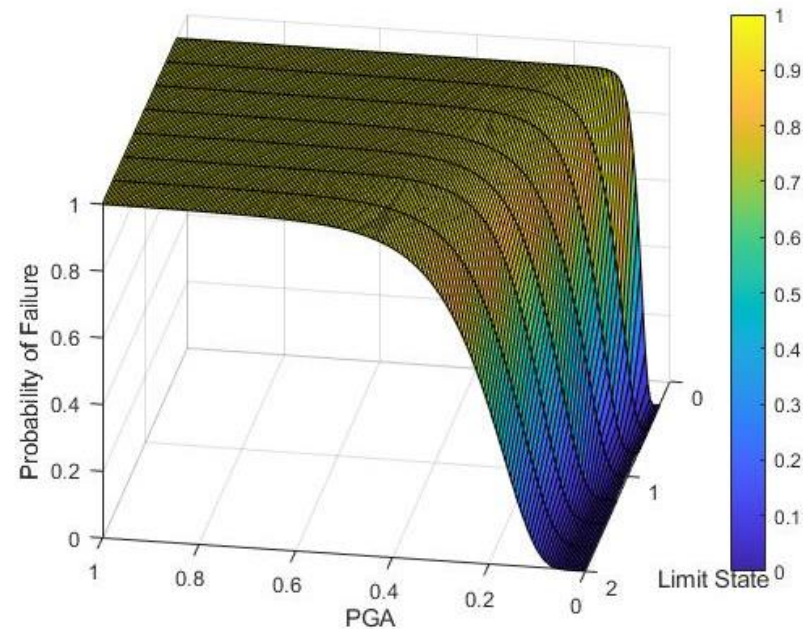

VIMEU00 Model

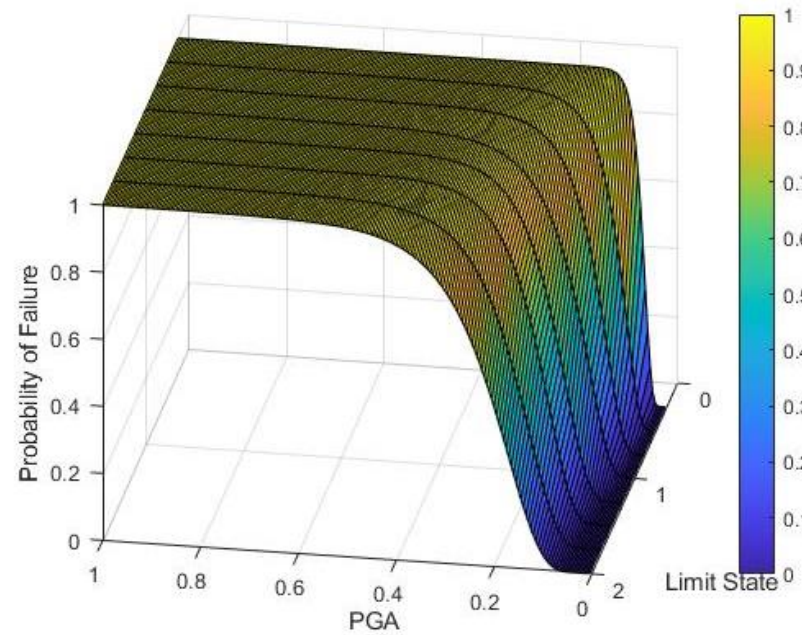

VIMEU01 Model

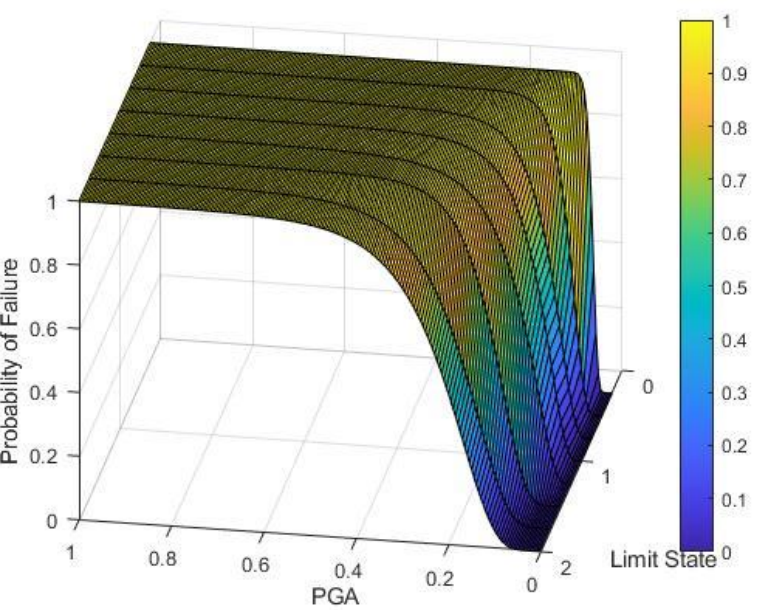

VIMEH00 Model

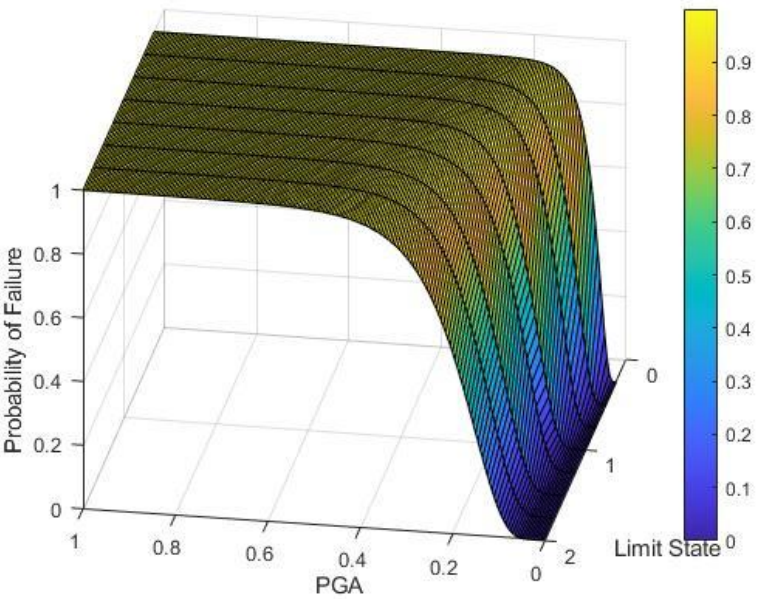

VIMEH01Model 


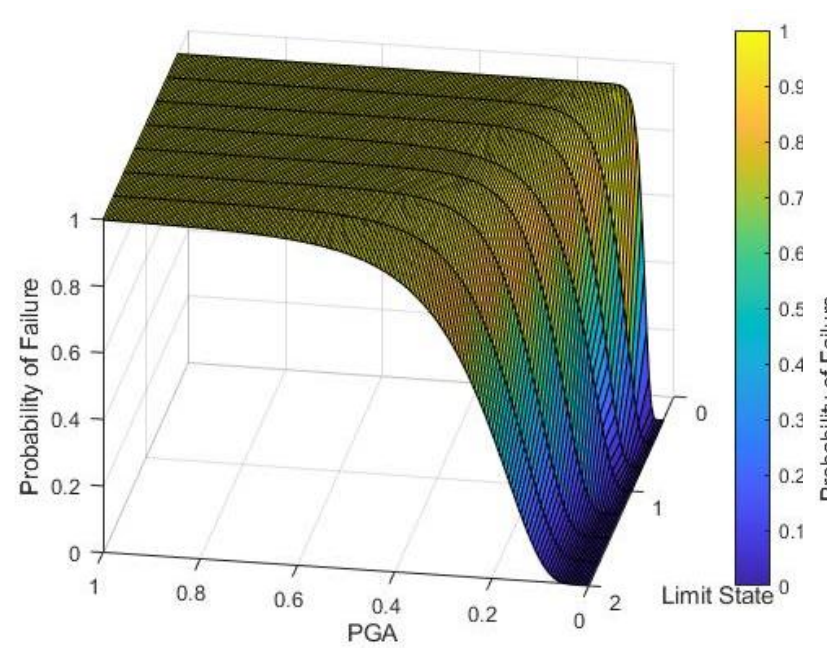

VIMEU03 Model

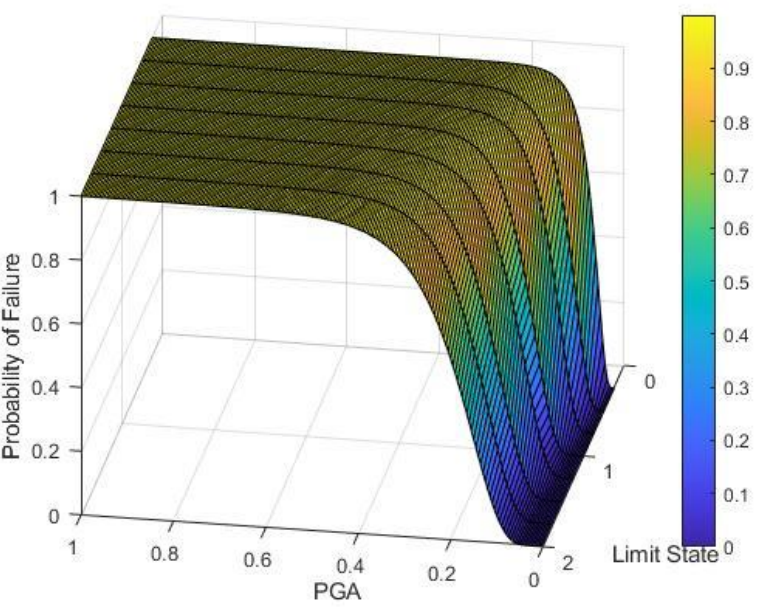

VIMEH03 Model

\section{Summary}

Three-story ordinary concrete reinforced moment-resisting frames are analyzed. An attempt is made to obtain seismic fragility curves in a precise and efficient way. An integrated structural reliability analysis method is adopted to perform seismic vulnerability analysis to overcome the computational challenge in the use of 3D analytical models. The concrete and steel strengths are modeled as random variables that follow the log-normal distribution. Fourteen different live-load distribution scenarios are considered. Ten earthquake ground motion records are selected for nonlinear response history analysis. Eight limit states based on the allowable drift ratio are assumed. A total of 1120 cases are explored on two ordinary personal computers. 112 fragility curves are generated, and seismic fragility surfaces are drawn from them. The proposed method is proven to efficiently produce seismic fragility curves even with the computationally demanding 3D analytical models. The use or occupancy change can convert initially regular structures to mass-eccentric systems having irregularities in plan or elevation, making more vulnerable to earthquake loads; the direct effects of vertical and in-plan irregularities on the seismic performance are confirmed from the derived fragility curves and surfaces. The log-normal cumulative functional forms of the vulnerability curves are provided for the design of irregular reinforced concreted 
frame structures. The seismic surface, firstly introduced in this study, provides the comprehensive information about structural performance under the earthquake events.

\section{References}

[1] Annual US earthquake losses estimated at \$4.4B. (n.d.). Retrieved November 30, 2020, from https://www.govcon.com/doc/annual-us-earthquake-losses-estimated-at-44b-0001.

[2] Department, P., \& 30, S. (2016, September 30). Deaths due to earthquakes worldwide 20002015. Retrieved November 30, 2020, from https://www.statista.com/statistics/263108/global-death-tolldue-to-earthquakes-since-2000/.

[3] Kwon, O. S., \& Elnashai, A. S. (2007): Fragility analysis of a bridge with consideration of soil-structure-interaction using multi-platform analysis. In Structural Engineering Research Frontiers (pp. $1-14)$.

[4] Melchers RE (1999): Structural reliability: analysis and prediction. 2nd Edition, John Wiley, New York, NY.

[5] Hanan Al-Nimry. 2019. "Development of Seismic Fragility Curves of RC Infilled Frame Buildings in Jordan.” Matec Web of Conferences 281 https://doi.org/10.1051/matecconf /201928101012.

[6] Hamzeh Shakib, Mehdi Nodeh, and Farashad Homaei. 2015. "Fragility Curve Development for Assessing Midrise Steel buildings with Buckling Resistant Braced System Having Vertical Irregularity. JSEE Vol 17, No.4. 
[7] Fang, N., \& Westcott, B. (2018, May 12). A decade on, heartache of deadly Sichuan quake still being felt. Retrieved December 09, 2020, from https://www.cnn.com/2018/05/11/asia/sichuanearthquake-anniversary-intl/index.html.

[8] Avadhoot Bhsale, Robin Davis, and Pradip Sarkar. 2018. "New Seismic Vulnerability Index for Vertically Irregular Buildings.” ASCE-ASME. J. Risk Uncertainty Eng. Syst., Part A: Civ. Eng., 4(3): 04018022.

[9] VU. Unnikrishnan, A.M. Prasad and B.N. RAO. 2013. "Development of fragility curves using high-dimensional model representation.” Earthquake Engng Struct. Dyn. 2013; 42:419-430.

[10] Lee, Young Joo, and Moon, Do Soo. 2014. "A new methodology of the development of seismic fragility curves.” Smart Struct. Syst. 14 (5): 847-867. https://doi.org/10.12989/sss.2014.14.5.847.

[11] Moon, Do Soo \& Lee, Young Joo \& Lee, Sangmok. 2018. Fragility Analysis of Space Reinforced Concrete Frame Structures with Structural Irregularity in Plan. Journal of Structural Engineering (United States). 144. 10.1061/(ASCE)ST.1943-541X.0002092.

[12] Bartlett, F. M., and J. G. Macgregor. 1996. "Statistical analysis of the compressive strength of concrete in structures." ACI Mater. J. 93 (2): 158-168.

[13] Mirza, S. A., and J. G. MacGregor. 1979. "Variability of mechanical properties of reinforcing bars.” J. Struct. Div. 105 (5): 921-937.

[14] American Society of Civil Engineers. 2017. Minimum design loads and associated criteria for buildings and other structures: ASCE/SEI 7-16. 